\title{
Hacia una política de la discapacidad encarnada
}

\section{Towards a politics of embodied disability}

\section{FRANCISCO SANTAMARÍA EGURROLA}

Universidad Internacional de la Rioja (UNIR)

francisco.santamaria@unir.net

ORCID: 0000-0003-3659-1263

Resumen. El tratamiento político de la discapacidad recibió un nuevo impulso en la segunda mitad del siglo XX. Dentro de este impulso, el denominado «modelo social de la discapacidad» sostiene que la discapacidad representa una construcción social fruto de la opresión que la sociedad capitalista ejerce sobre una minoría con deficiencias. De este modo, el modelo social de la discapacidad establece una absoluta dicotomía entre deficiencia y discapacidad, que relega nuestra condición corporal a las sombras del discurso. Pronto, en el seno de la comunidad de los «disability studies» surgieron voces críticas que alertaban de que el modelo social conduce a una discapacidad desencarnada. En un contexto diferente al de los «disability studies», Alasdair Macintyre ha realizado una propuesta sugerente, al llevar a sus últimas consecuencias las dimensiones animal y social del ser humano. Merece la pena explorar esta línea de investigación para llegar a una visión verdaderamente encarnada de la discapacidad.

Palabras clave: modelo social de la discapacidad, diversidad funcional, Alasdair Maclntyre, normalidad, cuerpo, animal.

Abstract. The political treatment of disability has received a new impulse during the second half of twentieth Century. Within this impulse, the so named "social model of disability" supports that disability is a social construct, derived from the oppression that a capitalist society exercises over a minority with impairments. Thus, the social 
model of disability establishes a complete dichotomy between impairment and disability which relegates our corporal condition to the shadow of the discussion. Soon, within the disability studies field grew critical voices alerting that the social model leads to a disembodied disability. In a different context of the disability studies, Alasdair Macintyre makes a suggestive proposal carrying to its last consequences this line of inquiry to arrive to a truly embodied vision of disability.

Keywords: social model of disability, functional diversity, Alasdair Maclntyre, normal, body, animal.

\section{Introducción. La politización de la discapacidad}

A lo largo de la segunda mitad del siglo XX ha tenido lugar una decisiva novedad en la forma en que la sociedad se ha ocupado de la discapacidad. Esta novedad ha residido en que la discapacidad ha dejado de tratarse exclusivamente como una cuestión personal -algo que atañe exclusivamente a quienes han visto severamente limitadas sus capacidades- para convertirse en un asunto social. Es más, en una cuestión política.

Evidentemente, no es que hasta entonces la sociedad no se hubiera ocupado de ninguna forma de las personas que sufren algún tipo de limitación, sino que la sociedad proporcionaba a estas personas algo que se enmarcaba en la simple benevolencia. No es que hubiera faltado, en términos generales, disposición de ayudar a las personas con necesidades especiales, para expresarlo con terminología actual, sino que estas ayudas procedían en general de la buena voluntad de sus familiares o de una sociedad dispuesta a prestar algunas ayudas básicas, pero no de una estructura social articulada en torno a la obligación de garantizarles un alto grado de autonomía, así como el efectivo ejercicio de sus derechos fundamentales.

Este cambio puede denominarse con justeza politización de la discapacidad, no tanto en el sentido de que ésta pase a formar parte de los enfrentamientos partidistas, sino en el de que la cuestión pasa a formar parte de la agenda política, en cuanto se trata ya de una cuestión de derechos y obligaciones. Esto es lo que significa que la discapacidad deja de constituir una cuestión meramente personal para convertirse en un asunto político: que la sociedad, al organizarse políticamente, no puede desen- 
tenderse de las personas con discapacidad, que no puede considerar esta como una cuestión exclusivamente personal y que está obligada a tomar cartas en el asunto. Que la discapacidad se ha politizado significa, en definitiva, que ha pasado a ser una cuestión relativa a la ordenación justa de la sociedad.

Este, llamemos, cambio de paradigma no aconteció de repente, sino que, tal como suele ocurrir en casi todas las transformaciones sociales, tuvo diversos precedentes sociales y diversas cristalizaciones. Como orientación para su más reciente historia, puede servir el resumen que realizan Agustina Palacios y Juan Romañach (Palacios y Romañach 2006, 48-60), quienes refieren el Movimiento por la Vida Independiente en Estados Unidos y la Unión de Personas con Deficiencias Físicas contra la Segregación (UPIAS, por sus siglas en Inglés) en el Reino Unido, como el inicio de la nueva forma de abordar la discapacidad a finales de la década de los años sesenta y comienzo de los setenta del siglo pasado. La movilización social y política de estos grupos tuvo características propias de acuerdo con el modelo de Estado y sociedad en cada uno de esos países.

En cualquier caso, cabría afirmar que en la segunda mitad del siglo pasado nos encontramos ante una «nueva» discapacidad. El problema reside en que este planteamiento sociológico de la discapacidad abre una brecha aparentemente insalvable con la concepción del cuerpo propia de una filosofía realista. ¿Es cierto que la respuesta justa y democrática a las necesidades de las personas con discapacidad requiere desoír su condición corpórea? ¿Puede la filosofía darnos claves complementarias a las sociológicas para ofrecer una adecuada respuesta social y política a la discapacidad?

\section{De la "nueva" discapacidad a su crítica}

\subsection{La invención de la nueva discapacidad}

Al hilo de la mencionada exposición de Palacios y Romañach, puede decirse que en Estados Unidos las reivindicaciones se alinearon más con los movimientos, en boga ya entonces, de los derechos civiles, que promo- 
vían también el reconocimiento de las minorías. En el Reino Unido, con un sistema más fuerte de protección social, la cuestión se desarrolló en cambio como algo ligado a la exigencia de derechos y a su teorización. Estos planteamientos, lógicamente, tuvieron posteriormente su expansión en otras regiones del planeta.

Sea como fuere, en el Reino Unido fue donde se desarrolló lo que se ha denominado «modelo social de la discapacidad», que es quizá el que ha tenido mayor influencia en el tratamiento de la discapacidad desde la perspectiva que he denominado «política». En cualquier caso, influyó decisivamente en los denominados «disability studies», que forman parte ya de la academia y representan toda un área de conocimiento y de reflexión social que, en mi opinión, comparte como elemento común el tratamiento político de la discapacidad al que me vengo refiriendo y de la que el modelo social puede considerarse pionero.

El modelo social es mucho más que una mera reivindicación de prestaciones pues concibe a las personas con discapacidad como una minoría discriminada por un orden social capitalista y aboga por un profundo cambio social, por una sociedad diferente, como condición necesaria para que resulten satisfechas las necesidades de las personas con discapacidad. Las personas que sufren discapacidad representan, según el modelo social un colectivo que sufre la opresión propia de una sociedad capitalista. Es la organización misma de la sociedad la que ha de cambiar. En esa línea se mueven los trabajos de Frances Hasler, Colin Barnes, Vic Finkelstein y, sobre todo, Mike Oliver, según referencian Shakespeare y Watson (2002, 3).

Una de las afirmaciones más significativas y emblemáticas del modelo social es que «quien discapacita es la sociedad». Así lo formuló la UPIAS en los Principios Fundamentales de la Discapacidad acordados en 1975 y publicados en 1976 (UPIAS 1975, 4). De todo ello se hacen cargo Shakespeare y Watson $(2002,4)$, quienes sintetizan la posición del modelo social británico, a la vez que inciden también en la diferencia con el estadounidense:

The British social model therefore contains several key elements. It claims that disabled people are an oppressed social group. It distinguishes between the impairments that people have, and the oppression which they experien- 
ce. And most importantly, it defines "disability" as the social oppression, not the form of impairment.

North American theorists and activists have also developed a social approach to defining disability, which includes the first two of these elements. However, as is illustrated by the US term "people with disabilities", these perspectives have not gone as far in redefining "disability" as social oppression as the British social model. Instead, the North American approach has mainly developed the notion of people with disabilities as a minority group, within the tradition of US political thought.

La discapacidad pasa a ser comprendida en el modelo social británico, no como una mera deficiencia orgánica («impairment»), sino como el conjunto de limitaciones derivadas de la organización social («disability»). Nos encontramos, así, ante un nuevo significado de la discapacidad, ante una «nueva» discapacidad. Esta propuesta resultaba solidaria de la crítica al tratamiento de la discapacidad como una cuestión médica. De hecho, el modelo social, además de una «des-institucionalización» (no reclusión en centros especiales) de las personas con discapacidad, reivindicaba también su des-medicalización. El modelo social se define a sí mismo como alternativo a lo que denomina «modelo médico» ${ }^{1}$.

\subsection{Malestar con el modelo social de la discapacidad}

Nos encontramos así ante una discapacidad que ha pasado a ser considerada una construcción social. Solidariamente con ello comienza lo que podemos considerar un proceso de des-corporización de la discapacidad. Resulta de gran interés a este respecto el mencionado artículo de Shakespeare y Watson (2002, 7 y 9), quienes se hacen cargo de los problemas prácticos y de las diferentes críticas vertidas sobre los desarrollos conceptuales habidos durante las décadas posteriores al nacimiento del modelo social. Entre esas voces críticas que mencionan Shakespeare y Watson se encuentran Jenny Morris, Liz Crow, Sally French y Carol Thomas,

1 Omito las referencias bibliográficas a la demanda de desinstitucionalización y desmedicalización de la discapacidad por haberse convertido tal demanda en un implícito omnipresente en los disability studies. 
quienes centran su crítica en las consecuencias derivadas de la distinción rígida entre deficiencia o limitación (impairement), por una parte, y discapacidad (disability) por otra, llevada a cabo en lo que denominan modelo social «fuerte». Shakespeare y Watson reconocen el gran cambio en la percepción de la propia situación que supuso para los interesados y la seducción que ejercía el modelo social: de repente, no eran ellos, las personas con discapacidad, sino la sociedad la que estaba mal y la que tenía la culpa; era la sociedad la que tenía que cambiar; las personas con discapacidad podían estar orgullosas de sí mismas y tenían derecho a reclamar derechos en vez de incurrir en la degradante dinámica de depender de la benevolencia y la caridad ajenas (Shakespeare y Watson 2002, 5).

Esta ganancia en autoestima trajo como consecuencia inmediata una mayor movilización reivindicativa por parte de las personas con discapacidad. Pero también acabó teniendo inconvenientes prácticos, precisamente por la radicalización de la separación entre lo biológico y lo social. La reivindicación necesitaba acentuar la opresión social, quedando en segundo plano la solución a los problemas físicos de la deficiencia. Aunque, como hemos visto, algunas investigaciones sociológicas sobre la discapacidad habían cuestionado críticamente diversos aspectos del modelo social antes que ellos, Shakespeare y Watson (2002) van más allá, para sostener que el modelo social ha dejado de ser útil y que precisa una reformulación. Parte importante de dicha reformulación reside, precisamente, en acoger de nuevo la situación física y material de las personas con discapacidad (Shakespeare y Watson 2002, 11).

Separar drásticamente lo biológico de lo social, tal como lo hace el modelo social «fuerte», en la práctica puede tener consecuencias dramáticas. Es posible, por ejemplo, que dejemos de preocuparnos por la seguridad vial, el control de armas, los programas de vacunación y la limpieza de minas (Shakespeare y Watson 2002, 13).

Así, pues, por mucho que no se desee incurrir en una perspectiva exclusivamente médica de la discapacidad, se impone abierta y rotundamente admitir que nos discapacitan tanto las barreras sociales como nuestros cuerpos (Shakespeare y Watson 2002, 15). La dificultad para marcar la frontera entre lo sensorial-biológico y lo cultural, ayuda a relativizar la 
diferencia entre deficiencia o limitación, por una parte, y discapacidad por otra. Los autores sugieren, en esta línea, tener en cuenta los desarrollos que en aquel momento aportaba el feminismo postmoderno, según el cual debe superarse la distinción sexo-género, con objeto de que el sexo mismo pase a formar parte de la teoría social. El análisis y el marco postmoderno aparecen a los ojos de estos autores como una posible indicación del camino que deben recorrer en adelante los estudios sobre la discapacidad. La discapacidad representa la quintaesencia de lo postmoderno por su carácter complejo, variable, contingente, además de que ella misma es plural (Shakespeare y Watson 2002, 19).

Una lógica postmoderna representaría el camino adecuado según ellos para superar las dicotomías entre un modelo médico/individual, por una parte, y el modelo social por otra; entre deficiencia o limitación corporal y discapacidad, etcétera. En conclusión, consideran que la teoría de la discapacidad ha de acoger todos los aspectos: corporales, psicológicos, culturales y políticos (Shakespeare y Watson 2002, 19)

Efectivamente, la discapacidad ha de incluir todas las dimensiones de la persona, pero especialmente ha de tenerse muy en cuenta la esencial vulnerabilidad del cuerpo, dada por nuestra condición animal. Con un razonamiento muy similar al de MacIntyre (2001), que tendremos ocasión de exponer más adelante en este trabajo, los autores apelan a nuestra profunda condición animal y alertan frente al dualismo occidental mente/cuerpo propiciado en su opinión por la Ilustración, que define al ser humano por sus capacidades racionales (Shakespeare y Watson 2002, 26).

Esto lleva como de la mano a estos autores a afirmar el carácter universal de la discapacidad, una situación que afecta de alguna manera a todos los seres humanos y que, por tanto, debería llevar a rechazar -quizá algo más fácil, entienden, desde el marco del pensamiento postmoderno y posestructuralista- la distinción entre discapacitados y no discapacitados como «dos estados ontológicos distintos» (Shakespeare y Watson 2002, 27). Romper esa distinción será el futuro de la discapacidad:

We believe that the claim that everyone is impaired, not just "disabled people”, is a far-reaching and important insight into human experience, with 
major implications for medical and social intervention in the twenty-first century (Shakespeare y Watson 2002, 29).

\subsection{La desaparición del cuerpo en el modelo social}

La línea argumentativa de estos autores ha tenido continuidad en otros trabajos. Entre ellos, deseo centrarme ahora en la propuesta de Huges y Paterson (2008), quienes ahondan en la crítica sugerida por Shakespeare y Watson, denunciando, ya en el título del artículo al que me voy a referir, la desaparición del cuerpo acaecida en el modelo social de la discapacidad. La propuesta de Huges y Paterson aboga, como alternativa al modelo social de la discapacidad, por una sociología del impedimento, que a su vez formaría parte de una sociología del cuerpo. Para el objetivo del estudio que aquí se está realizando representa un interés no pequeño el que estos autores reivindiquen, precisamente, una discapacidad encarnada.

Huges y Paterson critican al modelo social de la discapacidad el no haberse percatado de las posibilidades que, a su juicio, encerraba la sociología del cuerpo surgida en la década de los ochenta del siglo pasado, dando lugar a los «body studies». Consideran necesario superar la dicotomía impedimento/discapacidad, propia del modelo social, para que el cuerpo no quede «en las sombras del discurso» (Hughes y Paterson 2008, 109). En opinión de estos autores, la sociología del cuerpo lo que realiza es, precisamente, incorporar al discurso la corporalidad, convirtiendo así a nuestro cuerpo en objeto de estudio y reflexión social.

Aunque esta sociología del cuerpo se ha inspirado inauguralmente en el pensamiento posestructuralista y postmoderno, tal como puede encontrarse por ejemplo en Foucault, Huges y Paterson apelarán definitivamente al pensamiento fenomenológico como la mejor forma de acoger la corporalidad en la reflexión social. Pero, comencemos por la exploración de la «vía Foucault».

Consideran, en efecto, interesante que Foucault haya captado cómo el cuerpo es algo que interesa al poder. Para el filósofo francés, según estos autores «el cuerpo es un contingente histórico producto del poder» (Hughes y Paterson 2008, 115). Esto, explican, procede de que Foucault considera que no existe sensación sin lenguaje y el lenguaje es una herramien- 
ta del poder. Ello, también según los autores, tuvo gran influencia en los planteamientos feministas en torno a la relación entre sexo y género, al sostener que los símbolos sobre el cuerpo generan discursos culturales patriarcales. Huges y Paterson $(2008,116)$ sugieren que, al igual que sucedió en el ámbito del género, también en relación con el impedimento cabe crear una nueva identidad a través de símbolos que hablen de ellos en términos de positividad y orgullo, la cual serviría para una nueva política cultural de esa identidad. En el planteamiento foucaultiano, explican, los discursos sobre los cuerpos y la verdad del cuerpo son discursos de poder: gobierno y control de los cuerpos. El interés del posestructuralismo para estos autores estriba en la posibilidad de crear un discurso alternativo al discurso médico, que sería en su opinión un discurso de poder sobre los cuerpos (Hughes y Paterson 2008, 116).

La inspiración foucaultiana -explican- tuvo cierto recorrido, pero insuficiente, en algunos trabajos sobre la discapacidad, como ha sucedido en Arney y Bergen, en Liggett, Casling, Marks, Shakespeare o Chadwick. En todo caso, lo interesante de esa inspiración reside en la importancia de los discursos y del lenguaje (Hughes y Paterson 2008, 116).

Una muestra de la importancia concedida a los discursos lo representa la propuesta española de sustituir el término «discapacidad» por la expresión «diversidad funcional». Ese cambio lingüístico (al que en este trabajo no podemos dedicar más espacio) según sus mentores representaría una condición necesaria para el adecuado tratamiento social de la discapacidad, pues hablar de diversidad en vez de discapacidad sería más conforme con la dignidad de las personas que llamamos discapacitadas. A los efectos de lo que aquí estamos tratando resulta muy significativo que algunos autores hayan desarrollado su defensa de este giro lingüístico, precisamente apelando a las críticas de Focuault y Canguilhem a la idea de normalidad $^{2}$.

2 Los impulsores de este cambio terminológico son Javier Romañach, Manuel Lobato y Agustina Palacios (Romañach y Lobato 2005) y (Palacios y Romañach 2006). Profundizan en la idea de diversidad funcional desde la óptica de Foucault y Canguilhem autores como Susana Rodríguez Díaz y Miguel Ángel V. Ferreira (Rodríguez Díaz y Ferreira 2010a y 2010b) y (Ferreira 2010). Con un tono más crítico con la propuesta de Foucault se ha ocupado Melania Moscoso (Moscoso 2011). Aunque el giro lingüístico ha tenido 


\subsection{De Foucault a la fenomenología}

Huges y Paterson (2008), a pesar de todo, concluyen que la «encarnación» de la discapacidad y una adecuada sociología del cuerpo no puede provenir del posestructuralismo de Foucault. En efecto, haciéndose eco de Shakespeare y Watson, sostienen que «el concepto de biopolítica de Foucault quita al cuerpo su capacidad de acción y lo vacía de aspectos biológicos» (Hughes y Paterson 2008, 117).

En este punto, Huges y Paterson abogan por ensayar el pensamiento fenomenológico como vía adecuada para superar la dicotomía impedimento/discapacidad, a la que consideran un error dualista y desencarnado, propio del modelo social de la discapacidad, sin renunciar a la politización de la discapacidad inaugurada por dicho modelo. Desean encarnar la discapacidad sin incurrir tampoco en lo que consideran un planteamiento reaccionario de la discapacidad, es decir, un planteamiento no político de la misma.

La fenomenología, al combinar, en línea con Merleau-Ponty, el «cuerpo vivido» con los significados del «mundo experimentado», permitiría, según estos autores, articular el aspecto corpóreo y político del impedimento. «El cuerpo es al mismo tiempo sensorial y significativo» (Hughes y Paterson 2008, 118). Un ejemplo de ello lo representa el sufrimiento, considerado por el modelo social una categoría despreciable -no digna de consideración-, pues remitiría al planteamiento médico de la discapacidad, así como a la caridad y la compasión por parte del prójimo. Sin embargo, Huges y Paterson consideran que la fenomenología nos abre a la consideración del sufrimiento precisamente como articulación entre el cuerpo vivido y encarnado, y la opresión social. Reformular el sufrimiento ayudaría a entender la opresión social de forma encarnada (Hughes y Paterson 2008, 119).

En todo caso, es preciso para estos autores superar la dicotomía impedimento/discapacidad propia del modelo social y, podríamos nosotros

bastante éxito en España, tanto en la academia, como fuera de ella, tampoco han faltado críticos (Canimas Brugué 2015, Flórez 2016). 
decir, «socializar el impedimento», es decir, incorporar la cuestión de la discapacidad a la sociología del cuerpo, tal como se ha realizado en el ámbito de las identidades de género, raza, etcétera. El impedimento, argumentan, también puede formar parte de una identidad política, es decir, una diferencia corporal o material que rompe la homogeneidad opresiva de una sociedad:

Orgullo negro, orgullo gay, orgullo de las personas con discapacidad: todas son formas de una política de la propiocepción; de una política contemporánea de los cuerpos en la que los grupos excluidos deconstruyen las tiranías estética, política y económica (Hughes y Paterson 2008, 120).

Los autores de los que nos estamos ocupando tienen en común el deseo de no incurrir en dualismos (como los de impedimento/discapacidad, mente/cerebro, biológico/cultural, por ejemplo), ni en planteamientos reaccionarios, entendidos estos como planteamientos que no advierten la necesidad de una transformación de la estructura social. Se habla, por ejemplo, de rescatar el concepto de «sufrimiento» de sus asociaciones reaccionarias y trágicas (Hughes y Paterson 2008, 119). También resultaría reaccionario en el sentir de estos autores reinstaurar la primacía de la perspectiva médica (Hughes y Paterson 2008, 108).

\section{Una discapacidad verdaderamente encarnada y política}

\subsection{Nuestra irreductible condición animal}

Vamos a intentar a continuación mostrar la necesidad de una solución más «encarnada» de la discapacidad y hacer ver que las propuestas que se vienen dando desde la sociología del cuerpo resultan insuficientes en términos de «encarnación». Quizá el planteamiento reaccionario no tenga tanto que ver con la adopción de una determinada concepción del cuerpo, sino con otras coordenadas. O, dicho de otra forma, buscamos en lo que sigue una alternativa en que la denuncia de la opresión sufrida por las personas con discapacidad no requiera asumir los postulados de la socio- 
logía del cuerpo o del modelo social de la discapacidad, al menos en los términos filosóficos en que dichos postulados se articulan.

Merece la pena, por ello, prestar atención a la forma de afrontar la discapacidad que lleva a cabo MacIntyre en su obra «Animales racionales y dependientes. Por qué los seres humanos necesitamos las virtudes» (MacIntyre 2001). Esta obra, de obligada lectura -cabría decir- para el estudio de la discapacidad, posee la virtualidad de afirmar rotundamente, de manera conjunta, nuestra condición animal y nuestra condición social. Su afirmación de nuestra radical condición animal se presta poco a una consideración desencarnada de la discapacidad. La decidida apelación a nuestra condición social impide, por otra parte, mirar para otro lado ante la fragilidad humana.

En la exposición de MacIntyre sobre nuestra condición animal, resulta interesante para nuestro propósito la llamada de atención que efectúa sobre la tendencia filosófica a considerar nuestra dimensión animal como algo no propiamente humano y, consiguientemente, a producir un hiato entre lo natural-biológico y lo cultural. Así lo expresa en una recapitulación de su crítica a la tendencia filosófica a separar excesivamente lo animal y cultural en el ser humano:

La segunda naturaleza del ser humano, su naturaleza culturalmente formada como hablante de un lenguaje, es un conjunto de transformaciones parciales, pero sólo parciales, de su primera naturaleza animal. El ser humano sigue siendo un ser animal con identidad animal [...] He procurado [...] oponer reparos a la influencia cultural que tiene una imagen de la naturaleza humana según la cual el ser humano es un animal y adicionalmente algo más. De acuerdo con dicha perspectiva, el ser humano posee una primera naturaleza animal y, adicionalmente, una segunda naturaleza propiamente humana. [...] Se piensa que su relación con la naturaleza biológica es externa y contingente, y hasta tal punto que permite que se trace una única y nítida línea divisoria entre los seres humanos y los miembros de todas las especies no humanas (MacIntyre 2001, 68-69).

Resulta palmaria la continuidad que establece MacIntyre entre nuestra condición animal y la cultural. La cuestión no resulta meramente acadé- 
mica ni es en absoluto superflua, porque es en nuestra naturaleza animal donde comparece nuestra vulnerabilidad y dependencia de los demás. Es, precisamente, nuestra completa dependencia la que nos convierte en seres sociales, pues la única forma en que podemos llegar a lo que, con terminología aristotélica, MacIntyre llama «florecimiento» (o plenitud conforme a nuestro propio ser) es a través de los demás. Sólo con ayuda de los otros, normalmente comenzando por la de los padres, es como podemos alcanzar nuestra plenitud humana y ser, según su expresión, razonadores prácticos independientes. Los animales humanos y los no humanos somos semejantes en la posibilidad que poseemos de alcanzar la propia plenitud (MacIntyre 2001, 79). Conviene subrayar además que, cuando MacIntyre habla de plenitud humana no se refiere exclusivamente al adecuado desarrollo físico, sino, también y a la vez, al más profundo que viene dado por la consecución y desarrollo de las virtudes. En fin, nuestra plenitud sólo la podemos alcanzar con el concurso de los demás.

Somos dependientes en nuestra primera etapa como niños, en nuestra etapa final como ancianos y en otros momentos en los que se puede manifestar la propia fragilidad. Algunas personas, además, se encuentran afectadas por limitaciones que les obligan a vivir habitualmente en situación de dependencia de los demás. Son las que llamamos personas con discapacidad. Al propósito de la presente discusión es preciso tomar nota de cómo la argumentación de MacIntyre se presta poco a incurrir en el peligro advertido por Shakespeare y Watson de acabar interpretando la situación de discapacidad o no como «dos estados ontológicos distintos» (Shakespeare y Watson 2002, 27). Frente a eso, MacIntyre, reflexionando acerca de cómo hemos de organizar la sociedad, sostiene:

No sólo importa que en una comunidad de este tipo los niños y los discapacitados reciban la atención y el cuidado necesarios, sino también que quienes ya no son niños reconozcan en los niños lo que una vez fueron, que quienes no padecen aún ninguna disminución de sus capacidades por razón de su edad reconozcan en los ancianos lo que ellos serán en el futuro, y que quienes no están enfermos ni padecen ninguna lesión reconozcan en los enfermos y en quienes sí sufren una lesión lo que ellos mismos han sido a menudo y lo que serán y siempre podrían ser (MacIntyre 2001, 171). 


\subsection{Nuestra irreductible condición social y política}

Nos hemos adentrado ya en los aspectos sociales y políticos de la cuestión. MacIntyre opera con la noción clásica de bien común, de la que nos recuerda que es el tipo de bien que articula las dimensiones individual y social de nuestras vidas, sin que ninguna de ellas se pueda conseguir sin la otra. El bien individual no se puede conseguir al margen del bien común, pero este solo es tal si no impide el bien del individuo:

El bien del individuo no se encuentra subordinado al bien de la comunidad ni viceversa. Para conseguir e incluso definir su bien en términos concretos, el individuo primero debe identificar los bienes de la comunidad como bienes propios. Por lo tanto, no debe entenderse el bien común como la suma de bienes individuales, como un bien que se construye a partir de éstos. Al mismo tiempo, aunque la búsqueda del bien común de la comunidad sea para todos aquellos capaces de contribuir a él, un elemento esencial de su bien individual, el bien de cada individuo particular no queda reducido al bien común; y también existen, por supuesto, bienes comunes distintos de los bienes de la comunidad como un todo, como por ejemplo los bienes de las familias y de otros grupos sociales, los bienes de diversas prácticas ${ }^{3}$ (MacIntyre 2001, 129-130).

No obstante lo que se acaba de decir, MacIntyre se muestra pesimista respecto a la posibilidad de que el Estado moderno sea capaz de ofrecer una solución satisfactoria a nuestra fundamental condición de animales dependientes. Sin embargo, podría afirmarse que la posición política de MacIntyre no tiene nada de reaccionaria, en el grado en que introduce de lleno la obligación social para con la discapacidad:

Mi intención es imaginar una sociedad política que parta del hecho de que la discapacidad y la dependencia es algo que todos los individuos experimentan en algún momento de su vida y de manera impredecible, por lo que el interés

3 Con las «diversas prácticas», MacIntyre se está refiriendo a los distintos ámbitos de la actividad humana, para cada uno de los cuales rigen diversas normas o formas buenas de actuar. 
de que las necesidades que padecen las personas discapacitadas sean adecuadamente expresadas y atendidas no es un interés particular, no es el interés de un grupo particular de individuos concretos y no de otros, sino que es el interés de la sociedad política entera y esencial en su concepto del bien común. ¿Qué tipo de sociedad puede tener las estructuras necesarias para alcanzar un bien común de esa naturaleza? (MacIntyre 2001, 154)

Conviene subrayar que MacIntyre, al «universalizar» la discapacidad, en el sentido de que se trata de algo que nos afecta y sufrimos todos, lo que lleva a cabo es un importante cambio de perspectiva del planteamiento político de la discapacidad. Las personas con discapacidad dejan de ser un «grupo particular», y en ese sentido deja quizá de tener sentido hablar de un grupo oprimido. Se trata de un planteamiento en el que la discapacidad se plantea desde la óptica de una cuestión política general y no como algo referido a un colectivo, a una minoría o a una identidad.

\section{3. ¿Qué política?}

Por otra parte, MacIntyre sostiene que el Estado moderno no puede dar respuesta al problema de la discapacidad, debido a que en él no se articulan las sociedades inferiores, que son las directamente involucradas en las relaciones de interdependencia.

Ni la filosofía política ni tampoco la filosofía social de los últimos años contribuyen en general a dilucidar este aspecto, debido a que los trabajos que se han llevado a cabo, con algunas raras excepciones, no abordan el problema de los bienes comunes relativos a las asociaciones y las relaciones intermedias entre el Estado-nación y el individuo o la familia nuclear. No obstante, esa zona intermedia es precisamente la que hace falta comprender, puesto que en las relaciones que incorporan tanto el reconocimiento de la independencia de los razonadores prácticos como la conciencia de la dependencia humana, donde la justa generosidad es una virtud fundamental, las acciones presuponen, explícita o más a menudo implícitamente, la existencia de un bien común propio de un tipo de asociación que no puede existir bajo la forma del Estado moderno ni la de la familia de hoy en día (MacIntyre 2001, 155). 
El pesimismo de MacIntyre en este punto alude a un problema de filosofía política. Este filósofo entiende que una concepción política ajena a la idea clásica de bien común no ha dado muestras de haber resuelto adecuadamente el problema de nuestra profunda vulnerabilidad y dependencia. En la medida en que el bien común no actúa como concepto político, y -quizá es legítimo interpretar- en la medida en que la política articula sólo las relaciones del Estado con los individuos (los colectivos oprimidos quizá también responden a la lógica individual) no resulta políticamente resoluble a ojos de MacIntyre la cuestión de la discapacidad. El filósofo escocés afincado en Estados Unidos se aparta con su planteamiento del tratamiento de la discapacidad en clave de opresión de un colectivo y, por tanto, no da pie a tratarla tampoco en clave identitaria ni de orgullo alguno. Esta orientación característica de la postmodernidad resulta por completo ajena al pensamiento de MacIntyre.

Llegamos de este modo a un punto límite en nuestra investigación. Si se tiene en cuenta el profundo antiliberalismo de MacIntyre (De la Torre Díaz 2012, 306-311), podríamos preguntarnos si sus planteamientos resultan reaccionarios y cabe cuestionarse el alcance político de su propuesta. Sin embargo, su propio discurso (MacIntyre 2001, 154) contiene elementos para un tratamiento verdaderamente político de la discapacidad. De hecho, resulta de gran relevancia para lo que nos ocupa el papel que el profesor de Notre Dame otorga a la misericordia, con su apertura a miembros externos a la comunidad a la que se pertenece (MacIntyre 2001, 148). Cabe pensar quizá que es precisamente el estudio profundo de la discapacidad y las virtudes del reconocimiento de la dependencia (MacIntyre 2001, capítulo 10) lo que, abandonando los elementos más comunitaristas presentes en el resto de su obra, acaba abriendo su pensamiento a planteamientos universalistas y cosmopolitas.

\section{Conclusiones}

El tratamiento político de la discapacidad inaugurado y desarrollado a partir de los años sesenta del pasado siglo significó un avance importante para las personas que sufren algún tipo de discapacidad. Representa, en 
efecto, un progreso que la situación de las personas con discapacidad haya entrado en la agenda política. Sin duda, dicha politización -entendido ello sin ninguna connotación negativa- ha mejorado la situación vivida por millones de personas en el mundo. Sin embargo, hemos sido críticos con los argumentos desde los que se ha venido dando esa batalla. Y, al escribir este artículo, nos hemos fijado en un aspecto de especial relevancia: la amenaza de postular una antropología desencarnada como herramienta del discurso emancipador. La distinción característica del modelo social entre impedimento o deficiencia, por una parte, y discapacidad por otra ha llevado, como han denunciado Huges y Paterson, el impedimento a las sombras del discurso. Esto significa dejar en sombra nuestra propia condición corpórea.

La cuestión no resulta baladí porque comprender adecuadamente el alcance del cuerpo afecta profundamente a la identidad humana. Como recuerdan José Ángel Lombo y José Manuel Giménez-Amaya, el cuerpo es el carácter extenso del propio yo humano, y no una realidad viviente con independencia de él, de manera que el hombre accede al mundo no sólo «a través» de su cuerpo, sino «desde» él, «siendo» ese cuerpo (Lombo y Giménez-Amaya 2016, 28). Representa un error mayúsculo abordar la discapacidad como mera construcción social, como si las afecciones de la corporalidad no fueran significativas por sí mismas, como si la adecuada funcionalidad de los distintos órganos del ser humano no formaran parte de su integridad corporal.

El cuerpo es un organismo altamente complejo, un conjunto de órganos, cada uno de los cuales cumple una función diferenciada en orden al bien del conjunto. Posee el cuerpo, por tanto, una unidad sistémica. Dicha unidad de las partes respecto a la totalidad del individuo, de la que no da suficientemente cuenta el desarrollo mecanicista de la medicina en la Edad Moderna, es requerida tanto para la composición misma del organismo como para su dinamismo y actividad (Lombo y Giménez-Amaya 2016, 26 a 51). Y es precisamente la función que por su propia índole cumple cada uno de los diferentes órganos la que los hace necesarios. La función no es algo añadido a estos. Por eso, no debe subestimarse de ninguna manera -como lo hace el modelo social- el daño que inflige al ser huma- 
no la discapacidad. La adecuada respuesta sociopolítica a la discapacidad no puede hacerse, por ello, mediante su «desencarnación».

De esta forma, la visión llamemos desencarnada de la discapacidad resultaría solidaria con otros oscurecimientos de la corporalidad presentes en el pensamiento actual. En efecto, lo que tiene que ver con la manipulación genética de embriones humanos, la misma producción de seres humanos mediante fecundación in vitro, la teoría de género o las propuestas transhumanistas ${ }^{4}$, tienen en común su incidencia sobre el cuerpo humano. Constatar en el ámbito de la discapacidad una deriva que cuestiona de algún modo nuestra condición corpórea nos remite a un marco conceptual y cultural más amplio y proporciona un interés máximo a esa deriva. El adecuado tratamiento de la discapacidad, entendemos ahora, posee implicaciones importantes para una antropología cristiana. Se juega mucho esta antropología en la cabal comprensión del alcance corporal de la discapacidad, que no debe quedar difuminado al abordarla socialmente.

En este trabajo, tras hacernos eco de algunos autores que, en el marco de los «disability studies», han señalado el riesgo del ensombrecimiento de la corporalidad, hemos optado por exponer el pensamiento filosóficomoral de MacIntyre como una afirmación decidida e inequívoca de una discapacidad encarnada. Lo que hemos pretendido mostrar con la referencia a MacIntyre es que la concepción aristotélica del ser humano representa una excelente base para «radicalizar» la discapacidad, esto es, para comprenderla de una forma rotundamente encarnada, a la vez que como una exigencia de la comunidad política. Por otra parte, su planteamiento permite sacar el tratamiento político de la discapacidad de una órbita postmoderna y postmarxista, en la que las personas que sufren discapacidad son consideradas o bien un colectivo oprimido o bien una identidad necesitada de reconocimiento.

La concepción realista de MacIntyre y su cabal concepción del ser humano como animal avienta cualquier riesgo de «descorporizar» la discapa-

4 Resultan muy interesantes a este respecto, también por la convergencia de los enfoques, los estudios de Belén Liedo Fernández y Jon Rueda (Liedo Fernández y Rueda 2021) y de Mariano Asla (Asla 2019) publicados en esta misma revista, acerca de la compatibilidad o no del transhumanismo con la vulnerabilidad humana y con los límites de nuestra condición corpórea. 
cidad. Además, su propuesta es también decididamente social y política. El antiliberalismo del que ha hecho gala en sus obras y su escepticismo sobre la posibilidad de que el Estado moderno pueda dar respuesta a los problemas de la discapacidad, más que una invitación a desechar el pensamiento del escocés, representa una invitación a continuar avanzando, tanto en el estudio sociológico de la discapacidad, como en el pensamiento de MacIntyre, para explorar quizá felices convergencias. Articular una visión netamente encarnada de la discapacidad con un tratamiento verdaderamente político de la misma representa un desafío estimulante. En las páginas que ahora concluyen simplemente hemos intentado delinear el marco en que ese estudio podría llevarse a cabo en ulteriores investigaciones.

\section{Referencias}

Asla, Mariano, 2019. "Acerca de los límites, imperfecciones y males de la condición humana: El biomejoramiento desde una perspectiva tomista”, Scientia et Fides 7 (2), 77-95. DOI: http://dx.doi.org/10.12775/SetF.2019.01.

Canimas Brugué, Joan. 2015. “¿Discapacidad o diversidad funcional?”. Siglo Cero. Revista Española sobre discapacidad intelectual 46 (2): 79-97.

De la Torre Díaz, Javier. 2012. “Treinta años tras la virtud”. Proyección 246: 303-23. Ferreira, Miguel Ángel V. 2010. “De la minus-valía a la diversidad funcional: un nuevo marco teórico-metodológico”. Política y Sociedad 47 (1): 45-65.

Flórez, Jesús. 2016, "Neurodiversidad, discapacidad e inteligencias múltiples", Revista síndrome de Down 33: 59-64.

Hughes, Bill., \& Paterson, Kevin. 2008. "El modelo social de discapacidad y la desaparición del cuerpo: hacia una sociología del impedimento”. En Superar las barreras de la discapacidad: 18 años de "Disability and society", coord. por Len Barton, 107-23. Madrid: Ed Morata.

Liedo Fernández, Belén y Rueda, Jon. 2021. "In defence of posthuman vulnerability”. Scientia et Fides 9 (1): 215-39. DOI: https://doi.org/10.12775/SetF.2021.008. Lombo, José Ángel y Giménez Amaya, José Manuel. 2016, Biología y racionalidad. El carácter distintivo del cuerpo humano, Pamplona: Eunsa.

MacIntyre, Alasdair. 2001. Animales racionales y dependientes. Por qué los seres humanos necesitamos las virtudes, Barcelona: Paidós.

Moscoso, Melania. 2011. "La discapacidad como diversidad funcional”, Dilemata 7: 77-92. 
Palacios, Agustina y Romañach, Javier. 2006. El modelo de la diversidad: la bioética y los derechos humanos como herramientas para alcanzar la plena dignidad en la diversidad funcional. Madrid: Diversitas- AIES.

Rodríguez Díaz, Susana y Ferreira, Miguel Ángel V. 2010a. “Diversidad funcional: Sobre lo normal y lo patológico en torno a la condición social de la dis-capacidad". Cuadernos de Relaciones Laborales 28 (1): 151-72.

Rodríguez Díaz, Susana y Ferreira, Miguel Ángel V. 2010b. “Desde la dis-capacidad hacia la diversidad funcional. Un ejercicio de dis-normalización”. Revista internacional de sociología 68 (2): 289-309.

Romañach, Javier y Lobato, Manuel. 2005. "Diversidad Funcional, nuevo término para la lucha por la dignidad en la diversidad del ser humano", website Foro de Vida independiente, 26 de julio de $2009 \mathrm{http} / / /$ forovidaindependiente.org/diversidad-funcional-nuevo-termino-para-la-lucha-por-la-dignidad-en-la-diversidad-del-ser-humano/ No obstante, en dicha entrada se puede descargar el texto en pdf fechado en mayo de 2005, que es el que utilizo como referencia.

Shakespeare, Tom y Watson, Nicholas. 2002. "The social model of disability: an outdated ideology?”. Research in Social Science and Disability 2: 9-28.

The Union of The Physically Impaired against Segregation (UPIAS) And The Disability Alliance. 1975. Disponible en University of Leeds. Centre for Disability Studies Consultado el 22 de septiembre de 2021 https://disability-studies. leeds.ac.uk/library/author/upias/ 